\title{
Sleep architecture, insulin resistance and the nasal cycle: Implications for positive airway pressure therapy
}

\begin{tabular}{|c|c|}
\hline $\begin{array}{l}\text { Authors: } \\
\text { Catherine A.P } \\
\text { Alister Neill }{ }^{2} \\
\text { Angela Camp } \\
\text { Jim Bartley }{ }^{3} \\
\text { David E. Whit }\end{array}$ & Crofts $^{1}$ \\
\hline \multicolumn{2}{|c|}{$\begin{array}{l}\text { Affiliations: } \\
{ }^{1} \text { Faculty of Health and } \\
\text { Environmental Sciences, } \\
\text { Auckland University of } \\
\text { Technology, New Zealand }\end{array}$} \\
\hline \multicolumn{2}{|c|}{$\begin{array}{l}{ }^{2} \text { WellSleep Clinic, University } \\
\text { of Otago, New Zealand }\end{array}$} \\
\hline \multicolumn{2}{|c|}{$\begin{array}{l}{ }^{3} \text { Department of Surge } \\
\text { University of Otago, } \\
\text { New Zealand }\end{array}$} \\
\hline \multicolumn{2}{|c|}{$\begin{array}{l}{ }^{4} \text { BioDesign Lab, Auckland } \\
\text { University of Technology, } \\
\text { New Zealand }\end{array}$} \\
\hline \multicolumn{2}{|c|}{$\begin{array}{l}\text { Corresponding author: } \\
\text { Catherine Crofts, } \\
\text { ccrofts@aut.ac.nz }\end{array}$} \\
\hline \multicolumn{2}{|c|}{$\begin{array}{l}\text { Dates: } \\
\text { Received: } 09 \text { Jan. } 2018 \\
\text { Accepted: } 13 \text { Feb. } 2018 \\
\text { Published: } 28 \text { Mar. } 2018\end{array}$} \\
\hline \multicolumn{2}{|c|}{$\begin{array}{l}\text { How to cite this article: } \\
\text { Crofts CAP, Neill A, Campbell } \\
\text { A, Bartley J \& White DE. } \\
\text { Sleep architecture, insulin } \\
\text { resistance and the nasal } \\
\text { cycle: Implications for } \\
\text { positive airway pressure } \\
\text { therapy. J. insul. resist. } \\
\text { 2018;3(1), a34. https://doi. } \\
\text { org/10.4102/jir.v3i1.34 }\end{array}$} \\
\hline \multicolumn{2}{|c|}{$\begin{array}{l}\text { Copyright: } \\
\text { (C) 2018. The Authors. } \\
\text { Licensee: AOSIS. This work } \\
\text { is licensed under the } \\
\text { Creative Commons } \\
\text { Attribution License. }\end{array}$} \\
\hline \multicolumn{2}{|l|}{ Read online: } \\
\hline 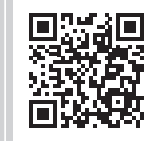 & $\begin{array}{l}\text { Scan this QR } \\
\text { code with your } \\
\text { smart phone or } \\
\text { mobile device } \\
\text { to read online. }\end{array}$ \\
\hline
\end{tabular}

Background: The global pandemic of metabolic disease is worsening. The metabolic theory of obesity proposes that hormonal changes, especially hyperinsulinaemia, precede metabolic disease development. Although quality sleep is recognised as a key factor for good health, less is known about disrupted sleep as a risk factor for hyperinsulinaemia.

Aim: To explore the relationship between sleep, especially sleep architecture and the nasal cycle, on insulin secretion in obstructive sleep apnoea (OSA) with comorbid metabolic disease. This review includes a discussion of the potential role of Rest-Activity-Cycler positive airway pressure (RACer-PAP), a novel non-pharmacological OSA treatment strategy.

Methods: A narrative review of all the relevant papers known to the authors was conducted. This review also included results from a polysomnographic sleep clinic pilot study $(n=3)$ comparing sleep efficiency of RACer-PAP to nasal continuous positive airways pressure $(\mathrm{n}-\mathrm{CPAP})$ in OSA patients.

Results: Metabolic disease is strongly associated with disturbed sleep. Sleep architecture influences cerebral hormonal secretion, lateral shifts in the autonomic nervous system and nasal airflow dominance. Disturbed sleep shortens short-wave sleep periods, decreasing insulin sensitivity and glucose tolerance. Improvements to metabolic function during n-CPAP treatment are inconsistent. If RACer-PAP demonstrates superior effects on sleep architecture and autonomic function, it may offer advantages in OSA patients with comorbid metabolic disease.

Conclusion: Improving sleep architecture by maintaining the nasal cycle proposes a novel non-pharmacological treatment paradigm for treating OSA with comorbid metabolic disease. Research is required to demonstrate if RACer-PAP therapy influences whole night sleep architecture, sympathovagal balance and markers of metabolic disease.

\section{Introduction}

The pandemic of metabolic disease, especially type 2 diabetes, cardiovascular disease, cancers, morbid obesity and dementias, is a global public health crisis carrying a significant economic burden. Despite some advances in the treatment of these conditions, preventative measures to date have made little impact on the increasing prevalence.

Obesity is considered to be the main aetiological driver of metabolic disease. Volitional control (eat less and move more) is usually promoted as the best way to manage obesity. However, there are a number of reasons why this approach is unlikely to succeed at a population level, especially neurological control and hormonal influences. The metabolic theory of obesity ${ }^{1}$ suggests that hormonal changes within the body preferentially partition circulating metabolic fuels into adipose tissues, thus increasing hunger and decreasing energy expenditure, prior to the development of obesity. This metabolic theory of obesity is strengthened by the recognition of impaired insulin homeostasis and hyperinsulinaemia being a recognised risk factor for metabolic disease. ${ }^{2}$ Emerging research suggests that hyperinsulinaemia precedes the development of both obesity and insulin resistance. ${ }^{1,3,4}$ Therefore, understanding the causes, and management, of hyperinsulinaemia may elicit novel ways of managing metabolic disease.

Sleep is being increasingly recognised as being a key factor in determining health. Sleep loss is considered a significant risk factor for impaired insulin homeostasis. ${ }^{5}$ However, little is known about the impact of disrupted sleep on the hormonal changes that influence insulin homeostasis. This review will consider a conceptual framework by which disrupted sleep leads to the 
development of hyperinsulinaemia, obesity, obstructive sleep apnoea (OSA) and metabolic disease focusing on sleep architecture and discuss a novel treatment strategy using a new type of positive airway pressure (PAP) therapy.

\section{Methods}

The literature was reviewed under the broad headings of noncommunicable disease, insulin and metabolic disease, type 2 diabetes, sleep staging and architecture, and the effect of sleep deprivation, targeting full-test English language studies. There was no date criterion. Articles were selected on the basis of providing a descriptive context associating metabolic disease with sleep quality. The final selection of articles was based on the authors' judgement of relevance, completeness and compatibility with epidemiological, pathological and clinical criteria.

A review of how pressurised breathing treatment affects the nasal airflow of OSA sufferers as this cohort commonly exhibit markers of metabolic disease is included. A new form of breathing therapy is introduced that could positively influence sleep architecture and sleep quality, and the findings from a pilot sleep study comparing sleep efficiency between these two treatments are presented. This new therapy, delivered by the Rest-Activity-Cycler positive airway pressure (RACerPAP) system, is a new variant of OSA pressurised breathing treatment that regulates and cycles inter-nasal airflow apportionment throughout the night.

\section{Review findings Insulin and metabolic disease}

Insulin is one of the central hormones of glucose homeostasis. Population studies demonstrate that elevations are an early marker of metabolic disease. ${ }^{2}$ Hyperinsulinaemia is a common aetiological factor for many metabolic diseases, especially type 2 diabetes, macro- and microvascular disease, certain cancers and dementias. Recent research suggests that hyperinsulinaemia may be present in a significant proportion of the population with both normal body mass indices and normal glucose tolerances, ${ }^{6}$ a clinically silent harbinger of the subsequent development of type 2 diabetes over $5-10$ years. ${ }^{7}$ Research is needed to understand the factors influencing the insulin responses within the body.

While it is likely that the management of hyperinsulinaemia will be multifactorial, some of the influencing factors are under the control of the autonomic nervous system (ANS).

\section{Sympathovagal imbalance}

It is recognised that maintaining healthy metabolic homeostasis requires exquisitely precise adjustments between the sympathetic and parasympathetic arms of the ANS. For example, insulin secretion is stimulated by vagal activation and inhibited by sympathetic adrenal activation. This process can be disturbed by numerous factors, including excessive sympathetic stimulation, such as stress. Sympathovagal, or autonomic, imbalance is associated with metabolic disease, although the direction of causality remains unclear. ${ }^{8}$

\section{Insulin physiology}

Insulin and glucagon are secreted from the beta cells of the pancreas in order to maintain blood glucose levels within a narrow therapeutic range. Insulin both decreases hepatic gluconeogenesis and increases cellular uptake of glucose in order to lower excessive blood glucose levels. It is generally believed that there is a basal secretion of insulin to maintain homeostasis, with additional insulin being secreted as a bolus to manage hyperglycaemia. Recent research suggests that insulin secretion occurs in a rhythmic and pulsatile manner with an ultradian periodicity ranging from 80 to $180 \mathrm{~min} .{ }^{9}$ This cycling is also modulated by fast oscillations that vary between 5 and $15 \mathrm{~min}$ and this latter time period is believed to be influenced by the individual's degree of insulin resistance. ${ }^{10}$ An increased frequency of the fast oscillations is hypothesised to either indicate or influence the degree of insulin resistance. Little is known about the factors that affect these modulated oscillations. However, it is recognised that insulin secretion is affected by a number of factors including other hormones (e.g. glucagon, adrenaline and cortisol), vagal nerve stimulation, food consumption, physical activity and sleep. The 'hourly-like' ultradian rhythm of insulin has also been shown to be tightly coupled to the ultradians of the ANS, cardiovascular system and neuroendocrine systems and contributes to sympathovagal balance. ${ }^{8,9}$

\section{Sleep deprivation as a risk factor for metabolic disease}

Over the last half century, changes in developed society and lifestyle have resulted in both adults and adolescents experiencing a $1.5-2 \mathrm{~h}$ reduction in sleep duration, as demonstrated by more than $30 \%$ of Americans who reported less than $6 \mathrm{~h}$ of sleep per night. ${ }^{11,12}$ In addition to societal changes, the ageing population experience a decline in sleep duration and increased sleep disruption. ${ }^{13,14}$ Sleep deprivation is implicated in disturbing the insulin oscillations, as sleep is known to affect hormone secretion, food consumption and physical activity and overall sympathovagal balance. Sleep deprivation arising from either sleep restriction or sleep disruption is known to affect a number of neurotransmitters and other hormones implicated in insulin homeostasis including, but not limited to, noradrenaline, adrenaline, leptin, ghrelin and cortisol. Sleep deprivation increases sympathetic nervous activity, resulting in increased cortisol secretion. ${ }^{5}$ Cortisol is known to have several direct effects on insulin homeostasis including the downregulation of GLUT4 transporters, thus increasing insulin resistance resulting in hyperinsulinaemia. ${ }^{2}$ Sleep deprivation also increases ghrelin and decreases leptin, resulting in the net effect of increased hunger (and food intake) and decreased physical activity. ${ }^{5}$ It is unclear whether the increased food intake is in response to hormonal, societal (i.e. under stress to perform despite sleep deprivation) or a combination of factors. As a result of these factors, sleep deprivation is now considered an obesity and type 2 diabetes risk factor. ${ }^{5,15,16}$ However, the direction of causality between sleep disruption and metabolic disease may need further determination. While sleep is inversely associated with body mass index (BMI) and waist girth, ${ }^{17}$ 
starvation is known to cause decreased sleep in rodents ${ }^{5}$ and low leptin levels can simulate these starvation conditions. As previously described, hyperinsulinaemia can invoke leptin resistance, causing a positive feedback cycle. It is reasonable to propose that non-pharmacologic efforts to improve sleep quality and total sleep should be investigated as part of a comprehensive strategy for metabolic disease management.

\section{Sleep architecture and rapid-eye- movement sleep}

Although the relationship between sleep quality and good health is recognised, it remains difficult to quantify 'quality sleep'. The Pittsburgh Sleep Quality Index differentiates 'poor' sleep from 'good' sleep using subjective sleep quality, sleep disturbances and daytime dysfunction, amongst other measures. ${ }^{18}$ However, a long-standing method of assessing quality sleep is by examining sleep architecture or the variations in sleep staging that occurs throughout the night. Sleep normally occurs in the four stages of non-rapid-eyemovement (NREM) sleep and one stage of rapid-eyemovement (REM) sleep (as shown in Figure 1). ${ }^{19}$

In a normal sleep cycle, people move between the lighter NREM stages of sleep (Stages 1 and 1) into the deeper stages (Stage 3 and 4), followed by a period of REM. ${ }^{19,20}$ The latter two NREM stages are collectively known as slow-wave sleep (SWS). SWS is considered the most restorative sleep and is strongly associated with sleep quality. ${ }^{21,22}$ SWS serves to restore the body through regulation of endocrine and autonomic variables, especially cortisol and human growth hormone.

During sleep, a healthy young adult experiences alternation in REM and NREM sleep staging approximately every 90-110 min throughout the duration of sleep, ${ }^{20}$ with REM accounting for approximately $20 \%-25 \%$ of the total sleep time. During the initial sleep period, sleep architecture in a healthy human is characterised with longer periods of SWS compared to REM sleep. As sleep progresses, the duration of SWS decreases and REM sleep increases. ${ }^{20}$ During sleep, there is an oscillation in parasympathetic or sympathetic tone that is synchronous with the NREM-REM cycle ${ }^{23}$ and may align with the oscillatory period of normal insulin secretion. ${ }^{24}$ Throughout SWS, the secretion rate of human growth hormone peaks and the ANS shifts from greater sympathetic tone to a greater parasympathetic tone. ${ }^{9,25}$ Changes in neuromodulatory systems, including the noradrenergic, serotonergic, histaminergic and cholinergic systems, and changes in local cortical connectivity, are all thought to be related to variations in SWS. ${ }^{26}$ In a small study $(n=9)$, preventing SWS over three nights without reducing overall sleep duration was shown to decrease insulin sensitivity and glucose tolerance. ${ }^{27}$

If sleep is disturbed, a person may not return to his or her previous sleep stage. Instead, he or she commences a new sleep cycle. This means that people with disturbed sleep typically spend less time in SWS and have increased hypothalamic-pituitary-adrenal (HPA) axis activation and subsequent cortisol secretion, and hence increased insulin resistance and potentially other metabolic disturbances. ${ }^{28,29}$ Sleep architecture is therefore recognised as a significant correlate and important marker for the HPA axis, ${ }^{28}$ and thus treatments that can affect the sleep architecture should be considered as options for treating metabolic disease.

\section{Obstructive sleep apnoea and sleep architecture}

A common cause of disrupted sleep is OSA. This condition manifests as repeated episodes of upper airway closure leading to repeated dips in blood oxygen tissue saturation causing recurring CNS arousals that disrupt normal sleep architecture..$^{30}$ The instinctive response to OSA is a state of arousal or semiawakening to reinstate tidal breathing; however, the sufferer may not be aware of these periods. Disease severity is measured using the apnoea-hypopnoea index (AHI), which is the mean number of apnoea and hypopnoea events per hour of sleep. ${ }^{31}$ Different studies have used different AHI values to define a diagnosis of OSA, but generally an AHI $<5$ is below the threshold for disease diagnosis.

\section{Obstructive sleep apnoea and metabolic disease}

There are conflicting reports regarding the prevalence of OSA in the general population. The 1993 Wisconsin Sleep Cohort study reported the prevalence of OSA as $4 \%$ in men and $2 \%$ in women (ages 30-60 years). ${ }^{32}$ However, more recent studies report a prevalence of up to $37 \%$ in men and $50 \%$ in women. ${ }^{31}$

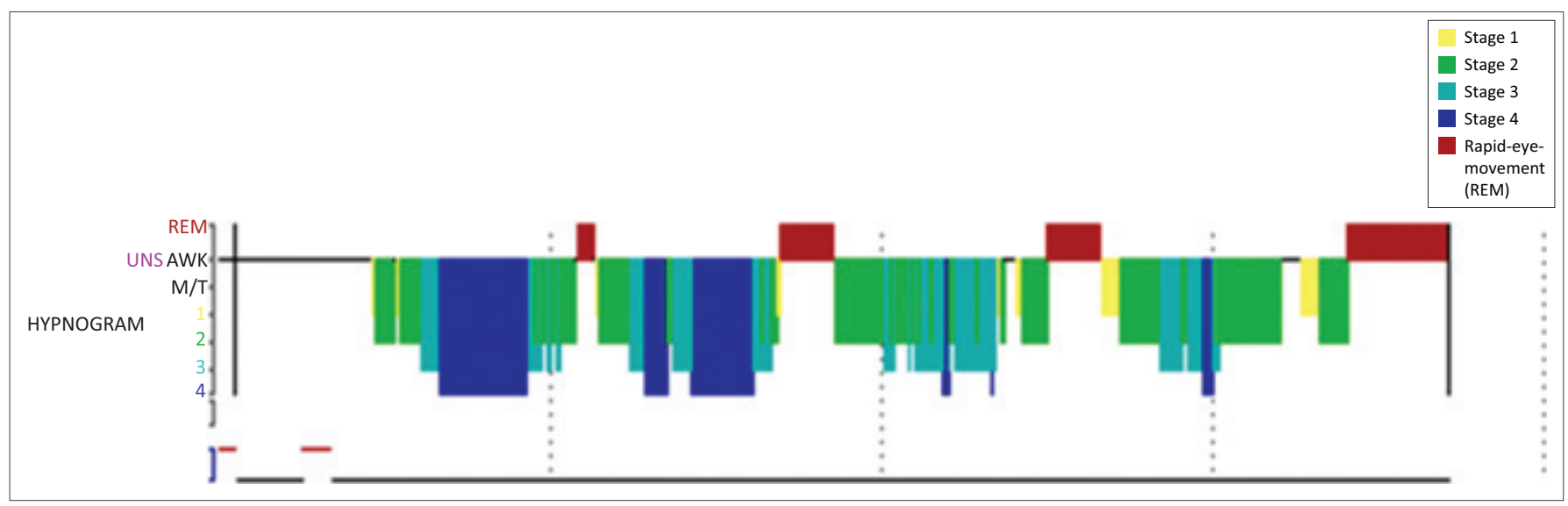

FIGURE 1: Adult hypnogram demonstrating the different sleep stages. The four stages of NREM sleep typically precede a period of REM sleep. 
The differences between studies may reflect differences arising from assessment methodologies, definitions, study designs, populations and also in the increasing prevalence of obesity.

People suffering from OSA are predisposed to experiencing reductions in SWS $S^{25,27,33,34,35}$ and REM sleep. ${ }^{20}$ In theory, a reduction in SWS will increase insulin resistance and could be one of the factors that lead to an increased risk for developing metabolic disease. Many metabolic diseases are associated with disturbed sleep architecture and shorter periods of SWS sleep. ${ }^{36,37,38}$ Even healthy individuals show reduced insulin sensitivity, when exposed to fragmented sleep, 15,37 although the direction of causality is uncertain. OSA is also independently associated with an increased prevalence of metabolic diseases linked to high morbidity and mortality, 39,40,41,42 although disease directionality is inconclusive. As many of these metabolic diseases are also associated with hyperinsulinaemia, it is plausible that hyperinsulinaemia and OSA may share a common pathogenesis.

Less is known about how OSA affects normal neuromodulatory functioning including sleep staging. However, NREM and REM sleep staging has been shown to be closely linked with the ultradian rhythms of alternating cerebral hemispheric activity $^{43,44}$ and the ultradians in ANS balance between parasympathetic and sympathetic dominance. ${ }^{45,46}$ This association is demonstrated by reductions in heart rate, blood pressure, respiration rates and body temperature that occur during NREM sleep. During REM sleep, heart rate, blood pressure, respiration rates and thermoregulation increase and with greater irregularity. Each of these two states demonstrates the variation in autonomic balance between the primarily parasympathetic and sympathetic states that are coupled to NREM and REM sleep stages.

\section{Management of obstructive sleep apnoea}

Obstructive sleep apnoea is currently managed by lifestyle measures (e.g. encouraging the patients to lose weight, avoid alcohol and not sleeping on their back or stomach) and by medical devices depending on the severity of the disease. People with moderate to severe OSA may be prescribed continuous positive airway pressure (CPAP) therapy. This device delivers a continuous supply of compressed air via a mask that covers the nose alone or both nose and mouth. CPAP therapy decreases daytime sleepiness but only causes slight to modest improvements in metabolic outcomes. ${ }^{47,48}$ This improvement is currently attributed to OSA sufferers realising a partial improvement in sleep architecture, ${ }^{49,50}$ which can plausibly be linked with subsequent decreases in sympathetic activity and cortisol levels.

A significant challenge to managing OSA is the lack of adherence to CPAP therapy. Although CPAP is routinely prescribed for use during all sleep periods, full adherence to CPAP is accepted to be at least $4 \mathrm{~h}$ per night on $70 \%$ of nights. ${ }^{51}$ This means that patient may not achieve good quality sleep which increases their risk for further development of metabolic disease. ${ }^{5}$

\section{Nasal cycle and the autonomic nervous system}

The nasal cycle is a normal ultradian physiological phenomenon that manifests in all mammals, ${ }^{52}$ where each nasal airway takes turns at conducting a greater apportionment of tidal airflow. The status of airflow dominance between the right and left nasal airways is correlated with sympathetic and parasympathetic dominant states, respectively, as regulated by the ANS, ${ }^{53,54}$ the lateralised ultradian rhythm of alternating cerebral hemispheric dominance ${ }^{55,56}$ and is tightly coupled to sleep staging $44,46,53,55,57,58$ and sleep position..$^{59}$ This suggests that the nasal cycle is strongly connected with sympathovagal balance. Nasal-applied continuous positive airway pressure (n-CPAP) is considered the gold standard of OSA treatment but has also been shown to abolish the nasal cycle in awake volunteers. ${ }^{60}$ The effect of abolishing the nasal cycle on sleep architecture is currently unknown. Although CPAP therapy causes modest improvements in sleep architecture, especially to SWS, it has no effect on REM sleep. ${ }^{50}$ The mechanisms for the improvements in sleep architecture are unknown, but decreasing sleep disturbances is likely to have beneficial effects on sleep architecture.

Despite there being a strong correlation between the duration of sleep and adherence to n-CPAP therapy, ${ }^{61}$ the inability of this treatment to positively influence sleep architecture during treatment has potentially prevented the full potential of improvement in metabolic disease from being realised. We postulate that abolishing the nasal cycle impedes restoration of sympathovagal balance, leading to a lack of metabolic benefits with CPAP therapy for OSA. ${ }^{47}$ This suggests that further research into PAP technology should account for the nasal cycle.

\section{Unilateral nostril breathing}

Unilateral nostril breathing (UNB) is a yogic breathing technique where the user occludes one nostril and breathes exclusively through the other. This has been shown to selectively activate either the sympathetic or parasympathetic branch of the ANS depending on the side of the occluded nostril. ${ }^{55,58}$. For example, right UNB selectively increases the electroencephalography (EEG) power in the left cerebral hemisphere ${ }^{62}$ and increases heart rate, ${ }^{63,64}$ while left UNB has been shown to reduce heart rate and selectively increase EEG power in the right cerebral hemisphere. Right UNB has also been shown to increase verbal skill performance and left UNB has been shown to increase spatial skill performance. ${ }^{65}$ This technique is believed to help restore the natural oscillations in the HPA axis which is important for sympathovagal balance.

Previous work has shown that in the awake state, blood glucose levels significantly increase during right UNB and lower during left UNB. ${ }^{58,66}$ This is supported by another study showing blood insulin levels are elevated during left nostril dominant breathing in a natural nasal cycle. ${ }^{9}$ The selective effects and benefits of UNB are proposed here to be 
implemented during sleep by the use of a second-generation PAP technology as a new approach for metabolic disease treatment.

\section{Rest-Activity-Cycler treatment}

The RACer-PAP system is a new instrument for treating OSA that utilises pressurised air selectively through one nostril and then the other to reinstate the normal rhythm of the nasal cycle that is abolished by n-CPAP therapy. ${ }^{60}$ The RACerPAP technology artificially reinstates nasal cycle patterns throughout sleep which is postulated to have a positive effect on sleep state architecture. $9,27,29,33,34,35,36,37,38,53$

A polysomnographic sleep clinic pilot study has recently been conducted with three n-CPAP-compliant OSA sufferers who received breathing treatment pressures ranging from $8 \mathrm{~cm} \mathrm{H}_{2} \mathrm{O}$ to $14 \mathrm{~cm} \mathrm{H}_{2} \mathrm{O}$. This study compared treatment efficacy during full overnight use of RACer-PAP and n-CPAP systems. With each individual acting as his or her own control, AHI was equivalent between nights for all patients. Arousal index (AI) was within night-to-night variation for all three participants between nights. Two participants experienced a $27.6 \%$ improvement in sleep efficiency, while one showed no change. Despite the limitation of this initial pilot study $(n=3)$, it does suggest RACer-PAP treatment might deliver improvement in sleep efficiency through regulation of inter-nasal airflows leading to improved sleep architecture.

\section{Implications and recommendations}

Given the disappointing results from the SAVE study on cardiometabolic outcomes, ${ }^{48}$ and slight to modest results for both blood glucose and blood pressure management, there is a strong rationale for exploring sleep architecture for the prevention and management of early metabolic disease. The understanding of the hypothalamic oscillations that are aligned with the nasal cycle and quality sleep architecture potentially offers a new therapy model for the management of metabolic disease in people without diagnosed OSA. Further investigations with the recently developed RACer-PAP technology may provide another non-pharmacological approach for the management of OSA-associated metabolic disease through the regulation of sleep architecture. Future research should collate sleep architecture and biometabolic markers, including cortisol, inflammatory markers, and insulin and glucose homeostasis measures, in people who are n-CPAP adherent and compare that baseline data with the same variables after those people have been transferred to RACer-PAP therapy after a period of at least 12 weeks. This would help determine the effectiveness of RACer for managing metabolic disease and may establish whether RACer aids in adherence to PAP therapy. Comparing adherence and biometabolic markers in people who are PAP therapy naïve and who are randomised to either RACer or n-CPAP therapy is also required.

\section{Conclusions}

Metabolic disease is strongly associated with disordered sleep architecture. RACer-PAP breathing therapy potentially offers a new form of non-pharmaceutical treatment for OSArelated metabolic disease. Further research is required to demonstrate if RACer-PAP therapy influences whole night sleep architecture and has effect on markers of metabolic disease.

\section{Acknowledgements}

The authors would like to thank KiwiNet, the Health Innovation Hub and Auckland University of Technology (AUT) for providing them financial support.

\section{Competing interests}

D.E.W. and J.B. declare that they are listed as co-inventors in a patent application of a new pressurised breathing technology. C.A.P.C., A.N. and A.C. declare that they have no financial or personal relationship(s) that may have inappropriately influenced them in writing this article.

\section{Authors' contributions}

C.A.P.C. and D.W. (AUT) were the project coleaders and were responsible for the concept and design, writing of the article, data retrieval and interpretation. A.N., A.C. and J.B. (University of Otago) were the reviewers and were responsible for data retrieval and interpretation

\section{References}

1. Ludwig DS, Friedman M. Increasing adiposity: Consequence or cause of overeating. JAMA. 2014;311(2):2167-2168. https://doi.org/10.1001/jama.2014.4133

2. Crofts $C$, Zinn C, Wheldon M, Schofield G. Hyperinsulinemia: A unifying theory of chronic disease? Diabesity. 2015;1(4):34-43. https://doi.org/10.15562/diabesity. 2015.19

3. Morita I, Tanimoto K, Akiyama N, et al. Chronic hyperinsulinemia contributes to insulin resistance under dietary restriction in association with altered lipid metabolism in Zucker diabetic fatty rats. Am J Physiol Endocrinol Metab. 2017;312(4):E264-E272. https://doi.org/10.1152/ajpendo.00342.2016

4. Crofts C. Understanding and diagnosing hyperinsulinaemia. AUT; 2015.

5. Knutson KL, Van Cauter E. Associations between sleep loss and increased risk of obesity and diabetes. Ann N Y Acad Sci. 2008;1129(1):287-304. https://doi. org/10.1196/annals.1417.033

6. Crofts C, Schofield G, Zinn C, et al. Identifying hyperinsulinaemia in the absence of impaired glucose tolerance: An examination of the Kraft database. Diabetes Res Clin Pract. 2016;118:50-57. https://doi.org/10.1016/j.diabres.2016.06.007

7. Hayashi T, Boyko EJ, Sato KK, et al. Patterns of insulin concentration during the OGTT predict the risk of type 2 diabetes in Japanese Americans. Diabetes Care. 2013;36(5):1229-1235. https://doi.org/10.2337/dc12-0246

8. Yang H. Sympathovagal imbalance in type 2 diabetes - Role of brainstem thyrotropinreleasing hormone. In: Masuo K, editor. Type 2 diabetes. InTech, 2013; p. 115-141. https://www.intechopen.com/books/type-2-diabetes/sympathovagal-imbalancein-type-2-diabetes-role-of-brainstem-thyrotropin-releasing-hormone

9. Shannahoff-Khalsa DS, Kennedy B, Yates FE, et al. Low-frequency ultradian insulin rhythms are coupled to cardiovascular, autonomic, and neuroendocrine rhythms. Am J Physiol Regul Integr Comp Physiol. 1997;272(3):R962-R968. https://doi. org/10.1152/ajpregu.1997.272.3.R962

10. Satin LS, Butler PC, Ha J, et al. Pulsatile insulin secretion, impaired glucose tolerance and type 2 diabetes. Mol Aspects Med. 2015;42:61-77. https://doi. org/10.1016/j.mam.2015.01.003

11. Bonnet MH, Arand DL. We are chronically sleep deprived. Sleep. 1995;18(10):908911. https://doi.org/10.1093/sleep/18.10.908

12. Spiegel K, Leproult R, Van Cauter E. Impact of sleep debt on metabolic and endocrine function. Lancet. 1999;354(9188):1435-1439. https://doi.org/10.1016/ S0140-6736(99)01376-8 
13. Van Cauter E, Leproult R, Plat L. Age-related changes in slow wave sleep and REM sleep and relationship with growth hormone and cortisol levels in healthy men. JAMA. 2000;284(7):861-868. https://doi.org/10.1001/jama.284.7.861

14. Van Cauter E, Spiegel K, Tasali E, et al. Metabolic consequences of sleep and sleep loss. Sleep Med. 2008;9:S23-S28. https://doi.org/10.1016/S1389-9457(08) 70013-3

15. Spiegel K, Knutson K, Leproult R, et al. Sleep loss: A novel risk factor for insulin resistance and Type 2 diabetes. J Appl Physiol. 2005;99(5):2008-2019. https://doi. org/10.1152/japplphysiol.00660.2005

16. Buxton OM, Pavlova M, Reid EW, et al. Sleep restriction for 1 week reduces insulin sensitivity in healthy men. Diabetes. 2010;59(9):2126-2133. https://doi.org/ 10.2337/db09-0699

17. Potter GDM, Cade JE, Hardie LJ. Longer sleep is associated with lower BMI and favorable metabolic profiles in UK adults: Findings from the National Diet and Nutrition Survey. PLoS One. 2017;12(7):e0182195. https://doi.org/10.1371/ journal.pone.0182195

18. Buysse DJ, Reynolds CF, Monk TH, et al. The Pittsburgh Sleep Quality Index: A new instrument for psychiatric practice and research. Psychiatry Res. 1989;28(2):193213. https://doi.org/10.1016/0165-1781(89)90047-4

19. Tasali E, Leproult R, Ehrmann DA, et al. Slow-wave sleep and the risk of type 2 diabetes in humans. Proc Natl Acad Sci U S A. 2008;105(3):1044-1049. https:// doi.org/10.1073/pnas.0706446105

20. Carskadon MA, Dement WC. Normal human sleep: An overview. In: Kryger MH Roth T, Dement WC, editors. Principles and practice of sleep medicine. 5 th ed. St Louis, MO: Elsevier Saunders, 2011, p. 16-26.

21. Bonnet MH. Sleep restoration as a function of periodic awakening, movement, or electroencephalographic change. Sleep. 1987;10(4):364-373. https://doi.org/ 10.1093/sleep/10.4.364

22. Åkerstedt T, Hume K, Minors D, et al. Good sleep - Its timing and physiological sleep characteristics. J Sleep Res. 1997;6(4):221-229. https://doi.org/10.1111/j. 1365-2869.1997.00221.x

23. Dijk D-J. Slow-wave sleep, diabetes, and the sympathetic nervous system. Proc Natl Acad Sci USA. 2008;105(4):1107-1108. https://doi.org/10.1073/pnas. 0711635105

24. Simon C, Brandenberger G. Ultradian oscillations of insulin secretion in humans. Diabetes. 2002;51(suppl 1):S258-S261. https://doi.org/10.2337/diabetes.51.2007. S258

25. Dijk D-J. Regulation and functional correlates of slow wave sleep. J Clin Sleep Med. 2009;5(2 Suppl):S6.

26. Saper CB, Scammell TE, Lu J. Hypothalamic regulation of sleep and circadian rhythms. Nature. 2005;437(7063):1257-1263. https://doi.org/10.1038/nature04284

27. Spiegel K, Tasali $E$, Leproult $R$, et al. Effects of poor and short sleep on glucose metabolism and obesity risk. Nat Rev Endocrinol. 2009;5(5):253-261. https://doi. org/10.1038/nrendo.2009.23

28. Balbo M, Leproult R, Van Cauter E. Impact of sleep and its disturbances on hypothalamo-pituitary-adrenal axis activity. Int J Endocrinol. 2010;2010.

29. Buckley TM, Schatzberg AF. On the interactions of the hypothalamic-pituitaryadrenal (HPA) axis and sleep: Normal HPA axis activity and circadian rhythm exemplary sleep disorders. J Clin Endocrinol Metab. 2005;90(5):3106-3114. https://doi.org/10.1210/jc.2004-1056

30. Strollo PJJ, Rogers RM. Obstructive sleep apnea. N Engl J Med. 1996;334(2): 99-104. https://doi.org/10.1056/NEJM199601113340207

31. Franklin KA, Lindberg E. Obstructive sleep apnea is a common disorder in the population - A review on the epidemiology of sleep apnea. J Thorac Dis. 2015;7(8):1311-1322.

32. Jordan AS, McSharry DG, Malhotra A. Adult obstructive sleep apnoea. Lancet. 2014;383(9918):736-747. https://doi.org/10.1016/S0140-6736(13)60734-5

33. Koren D, Katz LEL, Brar PC, et al. Sleep architecture and glucose and insulin homeostasis in obese adolescents. Diabetes Care. 2011;34(11):2442-2447. https://doi.org/10.2337/dc11-1093

34. Herzog N, Jauch-Chara K, Hyzy F, et al. Selective slow wave sleep but not rapid eye movement sleep suppression impairs morning glucose tolerance in healthy men. Psychoneuroendocrinology. 2013;38(10):2075-2082. https://doi.org/10.1016/j. psychoneuroendocrino

35. Van Cauter E, Knutson KL. Sleep and the epidemic of obesity in children and adults. Eur J Endocrinol. 2008:159(suppl 1):S59-S66. https://doi.org/10.1530/ EJE-08-0298

36. Pallayova $\mathrm{M}$, Donic $\mathrm{V}$, Gresova $\mathrm{S}$, et al. Do differences in sleep architecture exist between persons with type 2 diabetes and nondiabetic controls? JDST. 2010;4(2):344-352. https://doi.org/10.1177/193229681000400215

37. Stamatakis KA, Punjabi NM. Effects of sleep fragmentation on glucose metabolism in normal subjects. Chest. 2010;137(1):95-101. https://doi.org/10.1378/ chest.09-0791

38. Rao MN, Blackwell T, Redline S, et al. Association between sleep architecture and measures of body composition. Sleep. 2009;32(4):483-490. https://doi.org/ $10.1093 /$ sleep/32.4.483

39. Coughlin SR, Mawdsley L, Mugarza JA, et al. Obstructive sleep apnoea is independently associated with an increased prevalence of metabolic syndrome. Eur Heart J. 2004;25(9):735-741. https://doi.org/10.1016/j.ehj.2004.02.021

40. Tasali E, Mokhlesi B, Van Cauter E. Obstructive sleep apnea and type 2 diabetes: Interacting epidemics. Chest. 2008;133(2):496-506. https://doi.org/10.1378/ chest.07-0828
41. Campos-Rodriguez F, Martinez-Garcia MA, Martinez M, et al. Association between obstructive sleep apnea and cancer incidence in a large multicenter Spanish cohort. Am J Respir Crit Care Med. 2013;187(1):99-105. https://doi.org/10.1164/ rccm.201209-16710C

42. Bombois $S$, Derambure $P$, Pasquier $F$, et al. Sleep disorders in aging and dementia. J Nutr Health Aging. 2010;14(3):212-217. https://doi.org/10.1007/s12603-0100052-7

43. Barcaro U, Denoth F, Murri L, et al. Changes in the interhemispheric correlation during sleep in normal subjects. Electroencephalogr Clin Neurophysiol. 1986;63(2):112-118. https://doi.org/10.1016/0013-4694(86)90004-0

44. Shannahoff-Khalsa DS, Gillin JC, Yates FE, et al. Ultradian rhythms of alternating cerebral hemispheric EEG dominance are coupled to rapid eye movement and non-rapid eye movement stage 4 sleep in humans. Sleep Med. 2001;2(4):333346. https://doi.org/10.1016/S1389-9457(00)00066-6

45. Trinder J, Kleiman J, Carrington M, et al. Autonomic activity during human sleep as a function of time and sleep stage. J Sleep Res. 2001;10(4):253-264. https://doi. org/10.1046/j.1365-2869.2001.00263.x

46. Shannahoff-Khalsa DS, Yates FE. Ultradian sleep rhythms of lateral EEG, autonomic, and cardiovascular activity are coupled in humans. Int J Neurosci. 2000;101(1-4):21-43. https://doi.org/10.3109/00207450008986490

47. Pépin J-L, Tamisier R, Lévy P. Obstructive sleep apnoea and metabolic syndrome: Put CPAP efficacy in a more realistic perspective. Thorax. 2012:67(12):1025-1027. https://doi.org/10.1136/thoraxjnl-2012-202807

48. McEvoy RD, Antic NA, Heeley E, et al. CPAP for prevention of cardiovascular events in obstructive sleep apnea. N Engl J Med. 2016;375(10):919-931. https://doi. in obstructive sleep apnea. N
org/10.1056/NEJMoa1606599

49. Jurysta F, Kempenaers C, Lanquart J-P, et al. Long-term CPAP treatment partially improves the link between cardiac vagal influence and delta sleep. BMC Pulm Med. 2013;13(1):29. https://doi.org/10.1186/1471-2466-13-29

50. McArdle N, Douglas N. Effect of continuous positive airway pressure on sleep architecture in the sleep apnea-hypopnea syndrome: A randomized controlled trial. Am J Respir Crit Care Med. 2001;164(8):1459-1463. https://doi.org/10.1164/ ajrccm.164.8.2008146

51. Sawyer AM, Gooneratne NS, Marcus CL, et al. A systematic review of CPAP adherence across age groups: Clinical and empiric insights for developing CPAP adherence interventions. Sleep Med Rev. 2011;15(6):343-356. https://doi. org/10.1016/j.smrv.2011.01.003

52. Kahana-Zweig R, Geva-Sagiv M, Weissbrod A, et al. Measuring and characterizing the human nasal cycle. PLoS One. 2016;11(10):e0162918. https://doi. org/10.1371/journal.pone.0162918

53. Kimura A, Chiba S, Capasso R, et al. Phase of nasal cycle during sleep tends to be associated with sleep stage. Laryngoscope. 2013;123(8):2050-2055. https://doi. org/10.1002/lary.23986

54. Shannahoff-Khalsa DS, Kennedy B, Yates FE, et al. Ultradian rhythms of autonomic cardiovascular, and neuroendocrine systems are related in humans. Am J Physiol Regul Integr Comp Physiol. 1996;270(4):R873-R887. https://doi.org/10.1152/ ajpregu.1996.270.4.R873

55. Werntz D, Bickford R, Bloom F, et al. Alternating cerebral hemispheric activity and the lateralization of autonomic nervous function. Hum Neurobiol. 1982;2(1):3943.

56. Shannahoff-Khalsa DS. Lateralized rhythms of the central and autonomic nervous systems. Int J Psychophysiol. 1991;11(3):225-251. https://doi.org/10.1016/01678760(91)90017-R

57. Atanasov AT, Dimov PD, Dimitrov BD. Time periods in the nasal cycle during night sleep. Biol Rhythm Res. 2003;34(4):355-366. https://doi.org/10.1076/ brhm.34.4.355.26226

58. Shannahoff-Khalsa DS. Psychophysiological states: The ultradian dynamics of mind-body interactions. In: Bradley R, Harris R, Jenner P, editors. Int Rev Neurobiol. 80:1-249. New York Academic Press (Elsevier Scientific Publications); 2007.

59. Kutbay Özçelik H, Bayram M, Doğanay E, et al. Effects of body position on sleep architecture and quality in subsyndromal adults without apparent obstructive sleep apnea. Sleep Biol Rhythms. 2015;13(3):279-286. https://doi.org/10.1111/ sbr.12116

60. White DE, Bartley J, Shakeel M, et al. Nasal airway responses to nasal continuous positive airway pressure breathing: An in-vivo pilot study. J Biomech 2016;49(9):1887-1890. https://doi.org/10.1016/j.jbiomech.2016.04.034

61. Somiah M, Taxin Z, Keating J, et al. Sleep quality, short-term and long-term CPAP adherence. J Clin Sleep Med. 2012;8(5):489. https://doi.org/10.5664/jcsm.2138

62. Werntz DA, Bickford RG, Shannahoff-Khalsa DS. Selective hemispheric stimulation by unilateral forced nostril breathing. Hum Neurobiol. 1987;6(3):165-171.

63. Shannahoff-Khalsa DS, Kennedy B. The effects of unilateral forced nostril breathing on the heart. Int J Neurosci. 1993;73(1-2):47-60. https://doi.org/10.3109/00207 459308987210

64. Pal GK, Agarwal A, Karthik S, et al. Slow yogic breathing through right and left nostril influences sympathovagal balance, heart rate variability, and cardiovascula risks in young adults. N Am J Med Sci. 2014;6(3):145-151. https://doi. org/10.4103/1947-2714.128477

65. Jella SA, Shannahoff-Khalsa DS. The effects of unilateral forced nostril breathing on cognitive performance. Int J Neurosci. 1993;73(1-2):61-68. https://doi.org/ 10.3109/00207459308987211

66. Backon J, Kullok S. Changes in blood glucose levels induced by differential forced unilateral nostril breathing, a technique which affects both brain hemisphericity and autonomic activity. Med Sci Res. 1988;16:1197-1199. 